Bio - grafia. Escritos sobre la Biología y su Enseñanza. ISSN 2027

Edición Extraordinaria. p.p. 957- 969

Memorias del VIII Encuentro Nacional de Experiencias en Enseñanza de la Biología y la Educación Ambiental. III Congreso Nacional de Investigación en Enseñanza de la Biología.

\title{
REPRESENTAÇÕES SOBRE O CONCEITO DE NATUREZA: UM ESTUDO COM PROFESSORES DE CIÊNCIAS BIOLÓGICAS EM FORMAÇÃO
}

\author{
REPRESENTATIONS ON THE CONCEPT OF NATURE: A STUDY WITH BIOLOGY \\ TEACHERS YET TO FORM
}

SEVERO, THIAGO EMMANUEL ARAÚJO

1

DIAS, MÁRCIA ADELINO DA SILVA

2

\section{Resumo}

O ensino de Biologia, pautado na dialogia, reproblematiza conceitos e gera espaços democráticos de discussão sobre as dinâmicas da sociedade e do meio ambiente. Para este fim, objetivamos identificar como um grupo de estudantes do curso de Ciências Biológicas compreende o conceito de Natureza. Utilizamos um questionário e categorias teóricas de análise para identificar os elementos que emergiram nas respostas. Parte dos participantes da pesquisa reduziu a natureza apenas à fonte de alimento $(14,29 \%)$, ou símbolo de dominação, pertencente à humanidade $(35,3 \%)$, mas não se incluíram dentro das dinâmicas dos sistemas vivos. A fragmentação deste conceito pode ter bases na atual abordagem hegemônica dos conteúdos curriculares, priorizando um ensino pontual e a separação dos pólos homem/meio ambiente, sociedade/cultura.

Palavras-chave: Ensino de biologia; Educação ambiental; Natureza. 
Bio - grafia. Escritos sobre la Biología y su Enseñanza. ISSN 2027

Edición Extraordinaria. p.p. 957- 969

Memorias del VIII Encuentro Nacional de Experiencias en Enseñanza de la Biología y la Educación Ambiental. III Congreso Nacional de Investigación en Enseñanza de la Biología.

\section{Abstract}

The biology teaching needs to be based on dialogy, aiming to put in debate concepts and spaces of democratic discussions about the dynamics of the society and environment. For this purpose, we aimed to identify how a group of students of Biological Sciences understands the concept of Nature. We used a questionnaire and theoretical categories of analysis to identify elements that emerged in the answers. Some of the participants reduced nature to a source of food $(14,29 \%)$, others, to a symbol of domination, which belongs to mankind $(35,3 \%)$, but didn't included themselves in the dynamics of the living systems. A fragmentation of this concept may have bases in the current hegemonic curriculum on this approach, once they emphasize the separation of the poles man/environment, society/culture.

Key words: Biology teaching; Environmental education; Nature.

\section{Introdução}

As ciências naturais ampliam, hoje, as estratégias de compreensão dos fenômenos indo além do artifício de partir do fragmento para entender o todo, ou vice-versa. Agora procuram compreender o que está entre o que foi partido, aquilo que os une. Como propõe Latour (2009), Natureza e Cultura não são mais termos excludentes nem auto-explicativos, "mas sim aquilo que requer uma explicação conjunta" (p. 80). É nesta perspectiva que o ensino de ciências, da mesa forma, vem superando as explicações pontuais e os programas disciplinares fechados. A compreensão conjunta dos fenômenos, as explicações contextualizadas e a integração com formas outras de compreender o mundo em sua multiplicidade, têm diminuído cada vez mais o abismo que as fissões disciplinares construíram.

Garantir a construção de conceitos diversificados, abrir espaço para diferentes ideias e formas de construir, ler e narrar o mundo são metas da aventura humana de conhecer. $O$ ensino de ciências naturais, particularmente o de Biologia, tem um 958 
Bio - grafia. Escritos sobre la Biología y su Enseñanza. ISSN 2027

Edición Extraordinaria. p.p. 957- 969

Memorias del VIII Encuentro Nacional de Experiencias en Enseñanza de la Biología y la Educación Ambiental. III Congreso Nacional de Investigación en Enseñanza de la Biología.

compromisso com a vida - múltipla, mutante e diversa, e seu estudo deve ser pensado $e$ trabalhado didaticamente a partir das mesmas matrizes. Uma perspectiva dialética, que una, e não separe, de modo que as opiniões contraditórias não sejam precocemente descartadas.

Apesar do aspecto amplo e transdisciplinar possível às abordagens dos conteúdos das ciências naturais, alguns programas e métodos pontuais de trabalhar os currículos de ciências nas escolas retomam uma leitura superficial e compartimentalizada. Alguns tópicos estudados separadamente não permitem a devida integração entre seus diferentes conceitos, muito menos entre as demais disciplinas. Da mesma forma, não abrem espaço de diálogo para outros saberes que permeiam as salas de aula. Este aspecto hegemônico dificulta a compreensão e a construção de conhecimentos significativos, ou seja, de saberes pertinentes, tanto para os estudantes quanto para os professores.

No Brasil, os documentos que delineiam parâmetros para a educação básica, os Parametros Curriculares Nacionais (PCN), apontam que no ensino médio, o estudo da Biologia parte do pressuposto de que "as diferentes formas de vida estão sujeitas a transformações, que ocorrem no tempo e no espaço, sendo, ao mesmo tempo, propiciadoras de transformações no ambiente" (MEC/BRASIL, 2006, p. 14).

Moreira-Coneglian et. al., (2004, p. 40) constataram que os temas relacionados à ecologia, por exemplo, "[...] são muitas vezes, tratados de maneira teórica, o que acaba por distanciá-lo do cotidiano dos alunos, e os faz ter uma visão distante dos problemas ambientais". São estas atividades e discursos distantes da realidade da vida dos alunos que acaba criando barreiras, verdadeiros obstáculos epistemológicos, como posto por Bachelard (1977), entre as aulas e disciplinas herméticas sobre uma educação ambiental redundante e o sentido polissêmico atribuído ao estudo da Natureza.

Sob o ponto de vista ecológico, a educação ambiental constitui a adaptação (ecológica-evolutiva-social) do ambiente em que vivemos e dele, ao mesmo tempo, fazemos parte. Ou seja, homens e mulheres precisam conhecer estas interações, suas peculiaridades, fragilidades e potencialidades para que, desta forma, possam desempenhar suas funções na comunidade e exercer seu nicho ecológico dentro do ecossistema (EspíritoSanto, 2009). 
Bio - grafia. Escritos sobre la Biología y su Enseñanza. ISSN 2027

Edición Extraordinaria. p.p. 957- 969

Memorias del VIII Encuentro Nacional de Experiencias en Enseñanza de la Biología y la Educación Ambiental. III Congreso Nacional de Investigación en Enseñanza de la Biología.

A abordagem dos conteúdos na perspectiva da educação ambiental permite o desenvolvimento de um trabalho interdisciplinar, que se constrói de forma espontânea, como consequência das metodologias empregadas. Nesse intuito, o ensino torna-se interdisciplinar quando o professor proporciona ao estudante situações que the permitem construir seu conhecimento, pois este buscará, a partir das situações que se apresentam, as explicações que os outros componentes curriculares poderão fornecer, por meio de interações entre os conteúdos afins, conforme explicita Pereira (1993).

Sob esse ponto de vista, as metodologias em educação ambiental objetivam o contato direto entre o homem e o meio, o resgate e a conscientização de que este espaço é relevante à sobrevivência, à saúde, ao bem-estar do indivíduo; promovendo o desenvolvimento do sentido ético-social diante das diferentes problemáticas ambientais, a orientação do ser humano em relação ao ambiente e o exercício de cidadania, na busca de melhorias na qualidade de vida (Pereira, 1993). Assim, não apenas a escola, mas também os professores e professoras de ciências e biologia passam a assumir o compromisso social de proporcionar um conjunto de experiências que impulsione o estudante a atingir essa meta.

Os PCNs complementam que a construção de um mundo socialmente justo $e$ ecologicamente equilibrado requer responsabilidade individual e coletiva em níveis local, nacional e planetário (MEC/BRASIL, 2006). Desta forma, a abordagem de conteúdos atitudinais e procedimentais (Campos \& Nigro, 1999) durante as aulas de Ciências deverá se articular promovendo uma relação mútua entre os estudantes e o meio. Layrargues (2002, p. 9) afirma que a esta abordagem pode ser concebida, também, como uma ferramenta capaz de "[...] acelerar o processo de disseminação do pensamento ecológico no tecido social e promover a conversão para uma sociedade sustentável".

A partir das reflexões tecidas, objetivamos neste trabalho estudar a representação dos estudantes do primeiro ano do Curso de Licenciatura em Ciências Biológicas acerca do conceito de Natureza. Conceito chave que integra-se a uma dimensão mais ampla de todos os fenômenos, e que permite a construção de abordagens transdiciplinares, abrindo espaço para uma compreensão complexa do mundo. Desta forma, é de nosso interesse identificar como os futuros professores de ciências biológicas integram-se, aproximam-se ou distanciam-se deste conceito. 
Bio - grafia. Escritos sobre la Biología y su Enseñanza. ISSN 2027

Edición Extraordinaria. p.p. 957- 969

Memorias del VIII Encuentro Nacional de Experiencias en Enseñanza de la Biología y la Educación Ambiental. III Congreso Nacional de Investigación en Enseñanza de la Biología.

Neste tom, as seguintes questões de estudo direcionaram o norte desta pesquisa: Qual é a participação do ensino de biologia durante educação básica na construção das representações dos estudantes sobre a Natureza? O ensino de Biologia, a partir de seu caráter amplo, tem privilegiado a construção do conceito de Natureza durante a educação básica? As temáticas ecológicas, abordadas durante o ensino fundamental, subsidiaram conceitos amplos e dialéticos para a construção da Educação Ambiental?

\section{Percurso metodológico}

Nessa sessão dispomos os detalhes dos caminhos metodológicos que desenvolvemos para construir uma diversidade do conceito de Natureza e como esse se liga à prática do ensino de biologia. A fim de sistematizar o estudo, seguimos as seguintes etapas:

a. Caracterização da amostra - $O$ estudo foi realizado na Universidade Estadual da Paraíba com oitenta licenciandos, distribuídos em três turmas distintas do primeiro ano do curso de Licenciatura e Bacharelado em Ciências Biológicas, nos turnos da manhã e noite, durante o mês de fevereiro de 2009.

b. Construção e análise dos dados - Os foram construídos por meio de questionário contendo questões abertas e fechadas, versando sobre o que os estudantes concebem acerca dos conceitos de natureza. As questões permearam tanto as representações sobre a Natureza, quanto os aspectos aos quais ela é submetida.

c. Construção das categorias teóricas de análise - Os resultados que se apresentaram nas questões abertas dos questionários permitiram a construção de categorias com base na representação expressa pelos sujeitos da pesquisa em suas respostas, por meio da análise lexical conforme proposta por Bardin (1977). Durante a organização das categorias teóricas de análise a partir do léxico o critério principal consistiu na análise da amplitude da resposta, ou seja, se a resposta é direta ou indireta. Quando categorizadas como respostas diretas, procuramos agrupar a partir de termos 
Bio - grafia. Escritos sobre la Biología y su Enseñanza. ISSN 2027

Edición Extraordinaria. p.p. 957- 969

Memorias del VIII Encuentro Nacional de Experiencias en Enseñanza de la Biología y la Educación Ambiental. III Congreso Nacional de Investigación en Enseñanza de la Biología.

técnicos frequentes, de acordo com a pergunta, tendo a preocupação de perceber se o sujeito reduziu o conceito ou não. Quando categorizadas como respostas indiretas buscamos identificar os argumentos contidos nas respostas que se aproximam e as que se distanciam dos conceitos de natureza trabalhados em aula e contidos nos livros didáticos e a percepção do indivíduo quanto ao meio natural.

d. Análise dos dados - As análises foram realizadas com a utilização do software MODALISA 4.5, que favorece a interpretação qualitativa de dados quantitativos $e$ análise multivariada dos dados, contribuindo para a elaboração de categorias teóricas de análise e a identificação das representações dos estudantes. Tal ferramenta de pesquisa tem sido muito bem explorada em diversos trabalhos do gênero (Dias, 2008; Dias \& Nunez, 2006; Dias, Soares, Ramos, \& Nunez, 2005; Silva \& Dias, 2008).

\section{Resultados}

Representação acerca de meio ambiente, preservação ambiental e conceito de Natureza.

Podemos problematizar que estar ciente de sua participação nos fenômenos é um grande passo para a aquisição da 'consciência ambiental' pelos estudantes. De fato, a visão crítica sobre os conceitos aprendidos funciona como uma seleção àquilo que faz sentido, que é pertinente. Entender o seu papel dentro das relações que superam o indivíduo e que são da ordem da biosfera, é o primeiro passo para superação das simplificações e fragmentações do pensamento. Como argumenta Morin, a perspectiva dialógica pode ser traduzida pelo "conhecimento da integração das partes num todo" e este possa ser "completado pelo reconhecimento da integração do todo no interior das partes" (Morin, 2000, p. 26).

No que diz respeito ao conceito de Natureza, houve uma grande diversidade nas respostas dos estudantes. Quando perguntamos: Na sua concepção, o que é a Natureza? $15,71 \%$ dos estudantes têm a concepção de que é um 'conjunto' de tudo que existe; $14,29 \%$ 
Bio - grafia. Escritos sobre la Biología y su Enseñanza. ISSN 2027

Edición Extraordinaria. p.p. 957- 969

Memorias del VIII Encuentro Nacional de Experiencias en Enseñanza de la Biología y la Educación Ambiental. III Congreso Nacional de Investigación en Enseñanza de la Biología.

de que é apenas uma fonte de alimento e moradia, que pode ser utilizada pelos seres vivos; $14,29 \%$ a entendem como tudo aquilo que é vivo; e 7,14\% dos estudantes compreendem a Natureza como algo da ordem do que é místico ou ligado a crenças religiosas, como dádiva divina. As outras respostas diferem entre si, mas convergem para conceitos técnicos da área de ciências biológicas, como os de ecossistemas, por exemplo.

De fato, os estudantes compartimentalizaram este conceito como algo intrínseco à Biologia, ou a assuntos específicos desta disciplina. Não é vista qualquer intercomunicação deste conceito com outras áreas disciplinares. A noção de interação, principal fator que rege a dinâmica dos sistemas naturais, encontra-se ausente nas respostas. É provável que os participantes não tenham vivenciado um sistema de ensino baseado na transdisciplinaridade ou na união de conceitos, problematizando a Natureza não apenas como um cenário onde ocorrem estas interações, mas como a essência mesma de todos os processos. Segundo Pierson e Neves (2001), uma posição reducionista do docente pode exercer uma influência decisiva sobre o quão fragmentado serão os conceitos lecionados.

Considerando o caráter fragmentador dos conteúdos elencados para o ensino de Biologia, percebemos que a compreensão do conceito de Natureza torna-se confusa para a maioria dos estudantes. Por ser conceitualmente ampla $e$ influenciada por diversas tendências, o vício da técnica e o anseio do 'como fazer' reduzem seu escopo.

Dialogar, por exemplo, a Natureza a partir de conceitos ciêntíficos e místicoreligiosos, como vimos nas respostas, é uma prática incomcebivel para muitos futuros docentes. Ora, a Natureza é a matriz destas discussões e dos fenômenos que estudamos. Se expressa através das multiplicidades, transformando-se e recriando-se biológico-físico $e$ ontologicamente. Compreendê-la a partir de um referencial apenas compromete uma democracia cognitiva e subjuga a diversidade dos saberes (Almeida, 2010), "além, é claro, de desperdiçar uma infinidade de descobertas e sistematizações de conhecimento que emergem nas margens do conhecimento científico formal" (Idem, p. 38).

Neste sentido, precisamos estar atentos, também, a uma visão de Natureza viciada em uma cenologia, ou paisagem, que nos é familiar. 14,29\% entendem a Natureza como tudo aquilo que é vivo. Apesar da Biologia ser, por definição, a ciência que estuda a vida, não podemos esquecer que estas estruturas são recriações da matéria, um caso do possível. Os 
Bio - grafia. Escritos sobre la Biología y su Enseñanza. ISSN 2027

Edición Extraordinaria. p.p. 957- 969

Memorias del VIII Encuentro Nacional de Experiencias en Enseñanza de la Biología y la Educación Ambiental. III Congreso Nacional de Investigación en Enseñanza de la Biología.

elementos não-vivos, abióticos, são, também, elementos de interesse para a compreensão destas dinâmicas. As constantes transformações que movem nosso mundo têm berço nas relações biológicas e pré-biológicas que, apesar de suas diferenças evidentes, não se separam, como defende Henri Atlan (2001).

Trazer esta compreensão para o conceito de Natureza se faz necessário para a construção da 'consciência planetária', principalmente quando tratamos de professores em formação. Como mediadores primeiros do saber, imersos na práxis de ensinar, os professores devem estar atentos à multiplicidade de conceitos e à ecologia das ideias que se desdobram ao longo das aulas, a fim de dialogar questões tanto políticas e míticas quanto humanístico-sociais, que são, intrinsecamente, ambientais.

Esta compreensão ampla torna-se mais difícil frente aos paradigmas globais, onde - local separa-se do global e este influi sobre o primeiro. A construção cognitiva tanto de professores como de estudantes, assim como suas vivências, refletem diretamente no modo como estes sujeitos irão significar e compreender certos conceitos, bem como na forma que irão colocá-los em prática. Portanto essa compreensão ampla de Natureza deve partir da multiplicidade de saberes, tanto científicos quanto da tradição, significadas através da cultura, visto que todas as ideias, incluindo aquelas de caráter científico, são expressas através de fatores culturais.

A construção dos conceitos depende de diversos fatores intercomunicantes. Para Cobern et al., (1999), existem fatores extremamente importantes para a origem do conhecimento além daqueles de caráter racional, que são os metafísicos, ou não-racionais, relacionados a crenças, culturas ou estética. Desta forma podemos dizer que a construção e a compreensão do conceito de Natureza é mediada não somente pelo indivíduo, mas por toda a sociedade e o diálogo entre as diferentes culturas e saberes.

Os fatores de ordem racional estão relacionados às metodologias utilizadas ou a literatura específica, e na construção dos conceitos científicos não são autossuficientes. Para o estudante, estes precisam estar contextualizados $e$ interligados as suas experiências de vida. Cobern (1996) chama a forma como cada indivíduo percebe a realidade a sua volta de visão de mundo, não sendo esta meramente um subproduto da 
Bio - grafia. Escritos sobre la Biología y su Enseñanza. ISSN 2027

Edición Extraordinaria. p.p. 957- 969

Memorias del VIII Encuentro Nacional de Experiencias en Enseñanza de la Biología y la Educación Ambiental. III Congreso Nacional de Investigación en Enseñanza de la Biología.

cultura, mas o esqueleto das hipóteses e compreensões cognitivas dos indivíduos, constituindo o cerne do comportamento cotidiano.

O conceito de Natureza é intricado, uma vez que varia, de modo incisivo, de acordo com a cultura em questão. Na visão de algumas culturas, a Natureza nada mais é do que "substrato" para desenvolvimento humano, transformando-o constantemente em ferramentas e mão de obra disponível, como vimos nas respostas de $14,29 \%$ dos licenciandos participantes da pesquisa. De acordo com Dean (1996), esta situação esta ligado ao desenvolvimento da humanidade que transforma o mundo natural, muitas vezes reduzindo-o a paisagens, domesticando-o e moldando para que se adéque a si.

Quando foi dirigida a questão: Na sua concepção, a quem pertence a natureza? aos professores em formação participantes percebemos que 52,9\% acham que a natureza pertence a todos os seres vivos; outros $35,3 \%$ acreditam que pertence à humanidade, $7,8 \%$ disseram que não pertence a ninguém e 3,9\% destacaram que não pertence ao homem.

A quase unânime condição de pertencimento a qual os participantes caracterizaram a Natureza mostra, principalmente a partir do grupo que a classificou como pertencente à humanidade (35,3\%), traços de uma visão mercantilista onde se normalizou a apropriação dos espaços em favor do desenvolvimento capitalista. Esta visão é citada por Stillman (1977), ao descrever a influência cultural na America Latina. Para o autor, estas culturas de dominação têm origem, principalmente, no ocidente, a partir das quais se tem orientado uma concepção reduzida de Natureza, interpretada apenas como objeto de domínio. Esta representação demonstra grande apelo ao racionalismo, indicando que a construção deste conceito nos indivíduos tem grande repercussão no padrão econômico atual.

Resultados semelhantes foram descritos durante uma pesquisa com alunos do ensino básico em São Paulo. Moreira-Coneglian et. al., (2004) constataram que a contextualização dos conteúdos aprendidos em sala coloca-se como uma proposta de grande eficácia na internalização dos conteúdos. Esses pesquisadores afirmaram que "[...] 0 contato com os ambientes mais próximos também proporciona o desabrochar de novas visões, sentimentos, críticas e mudança de valores, o que é desejado em programas de educação ambiental para que esta seja eficiente e transformadora" (Moreira-Coneglian et al., 2004). 
Bio - grafia. Escritos sobre la Biología y su Enseñanza. ISSN 2027

Edición Extraordinaria. p.p. 957- 969

Memorias del VIII Encuentro Nacional de Experiencias en Enseñanza de la Biología y la Educación Ambiental. III Congreso Nacional de Investigación en Enseñanza de la Biología.

\section{Considerações finais}

Acreditamos que a identificação e o estudo das representações sobre o conceito de Natureza por este grupo de professores em formação nos põe diante de diálogos formativos que compreendem vários mundos distintos: a sua experiência como alunos do ensino médio, a sua trajetória como professores em formação, e a constante construção de sua práxis e identidade docentes durante o curso de Licenciatura em Ciências Biológicas. Esta posição privilegiada nos é muito rica para discutir as estratégias e objetivos que o ensino de Biologia precisa adotar, a fim de renovar-se perante os paradigmas de nosso tempo. Este estudo nos proporcionou da mesma forma, acesso a um escopo mais amplo sobre a gênese da construção da responsabilidade social e ética, envolvendo a preservação dos ambientes naturais, a partir das estratégias didáticas em Educação Ambiental.

Esperamos que estas reflexões possam servir de subsídios para outras mais, assim como trouxeram para nós e para os participantes da pesquisa oportunidade de diálogo e reflexão sobre nosso papel enquanto educadores e aprendizes frente às problemáticas ambientais e a um conceito amplo de Natureza, que não se reduz a paisagens, mas integra e complementa a tudo e todos.

A fim de facilitar o diálogo entre o currículo de Biologia e a realidade social de educadores e aprendizes, propomos, a partir dos resultados desta pesquisa, a necessidade de um eixo integrador que privilegie o diálogo e a fluidez entre as diversas manifestações e vertentes do conhecimento e da cultura: a Natureza. Desta forma, sinalizamos a importância que os cursos de Licenciatura na área de ciências naturais como pontos estratégicos na formação de professores, uma vez que se tornam palco de diálogos e discussões sobre sua própria formação e objetivos enquanto educadores. Espaços nos quais sejam priorizadas as discussões sobre a responsabilidade assumida pelos futuros professores em relação ao currículo do ensino básico, as questões ambientais e as perspectivas futuras para a educação.

Por fim, destacamos a necessária superação da fragmentação dos componentes que compõem os currículos dos cursos de formação de professores de Biologia, voltando-se na 
Bio - grafia. Escritos sobre la Biología y su Enseñanza. ISSN 2027

Edición Extraordinaria. p.p. 957- 969

Memorias del VIII Encuentro Nacional de Experiencias en Enseñanza de la Biología y la Educación Ambiental. III Congreso Nacional de Investigación en Enseñanza de la Biología.

direção de uma visão menos individualista do conhecimento, abrindo espaço para a construção de uma concepção crítico-social de educação.

\section{Referências}

Almeida, M. d. C. d. (2010). Complexidade, saberes científicos, saberes da tradição. São Paulo: Editora Livraria da Física.

Atlan, H. (2001). Viver e conhecer. Cronos. Revista do Programa de Pós-Graduação em Ciências Sociais da UFRN, 2(2).

Bachelard, G. (1977). Epistemologia. Escritos organizado por Dominique Lecourf. Rio de Janeiro: Zahar Editores.

Bardin, L. (1977). Análise de conteúdo. Lisboa: Edições 70.

Campos, M. C. C., \& Nigro, R. G. (1999). Didática de ciências: o ensino-aprendizagem como investigação. São Paulo: FTD.

Cobern, W. W. (1996). Wordview Theory and Conceptual Change in Science of Education. Journal of Science Education, 5(80), 579-610.

Cobern, W. W., Gibson, A. T., \& Underwood, S. A. (1999). Conceptualization of nature: an interpretive study of 16 ninth graders' everyday thinking. Journal of Research in Science Teaching(36), 541-564.

Dean, W. (1996). A Ferro e fogo: a história e a devastação da mata atlântica brasileira. São Paulo: Companhia das Letras. 
Bio - grafia. Escritos sobre la Biología y su Enseñanza. ISSN 2027

Edición Extraordinaria. p.p. 957- 969

Memorias del VIII Encuentro Nacional de Experiencias en Enseñanza de la Biología y la Educación Ambiental. III Congreso Nacional de Investigación en Enseñanza de la Biología.

Dias, M. A. d. S. (2008). Dificuldades na aprendizagem dos conteúdos de Biologia e as concepções alternativas: constatações a partir do índice de aproveitamento nas provas de múltipla escolha dos Vestibulares da UFRN, no período entre 2001 e 2008. (Doutorado em Educação), Universidade Federal do Rio Grande do Norte, Natal.

Dias, M. A. d. S., \& Nunez, I. B. (2006). Dificuldades de aprendizagem nos conteúdos de biologia: Um reflexo nos resultados das provas objetivas do vestibular da URFN no período de 2003 a 2006. Paper presented at the Congresso ANPAE, Natal.

Dias, M. A. d. S., Soares, W. C., Ramos, I. C. d. O., \& Nunez, I. B. (2005). Análise do índice de aproveitamento das questões objetivas das provas de química e de biologia do vestibular da UFRN: um estudo comparativo dos candidatos de escolas públicas e privadas no período de 2003 a 2005. Paper presented at the V Encontro Nacional de Pesquisa em Educação em Ciências (V ENPEC).

Espírito-Santo, A. P. d. (Producer). (2009, 2009). Ecologia e Educação Ambiental. Retrieved from http://www.ufpa.br/npadc/gpeea/artigostext/Ecologia_EdAmbiental.pdf

Latour, B. (2009). Jamais fomos modernos: ensaio de antropologia simétrica (Segunda Edição ed.). Rio de Janeiro: Editora 34.

Layrargues, P. P. (2002). Muito prazer, sou a educação ambiental, seu novo objeto de estudo sociológico. Paper presented at the I Encontro da Associação Nacional de Pós Graduação e Pesquisa em Ambiente e Sociedade, Indaiatuba.

MEC/BRASIL. (2006). Parâmetros Curriculares Nacionais, Ciências da Natureza, Matemática e suas Tecnologias. Brasília: MEC/SEF.

Moreira-Coneglian, I. R., Diniz, R. E. d. S., \& Bicudo, L. R. H. (2004). Educação ambiental em praça pública no município de Botucatu/SP. Revista Ciência em Extensão, 3(1), 3952. 
Bio - grafia. Escritos sobre la Biología y su Enseñanza. ISSN 2027

Edición Extraordinaria. p.p. 957- 969

Memorias del VIII Encuentro Nacional de Experiencias en Enseñanza de la Biología y la Educación Ambiental. III Congreso Nacional de Investigación en Enseñanza de la Biología.

Morin, E. (2000). Da necessidade de um pensamento complexo. In F. Menezes \& J. M. d. Silva (Eds.), Para nevegar no século XXI. Porto Alegre: Sulina; Edipucrs.

Pereira, A. B. (1993). Aprendendo Ecologia através da Educação Ambiental. Porto Alegre: Sagra-Luzzatto.

Pierson, A. H. C., \& Neves, M. R. (2001). Interdisciplinaridade na Formação de Professores de Ciências: conhecendo obstáculos. Revista Brasileira de Pesquisa Em Educação Em Ciências - Porto Alegre, 1(2), 19-30.

Silva, F. J. D. d., \& Dias, M. A. d. S. (2008). As representações que os estudantes do PROBÁSICA têm acerca da sua profissão: Elementos para refletir sobre a ação docente. Paper presented at the III CONGRESSO INTERNACIONAL SOBRE PESQUISA (AUTO) BIOGRÁFICA, Natal - RN.

Stillman, C. W. (1977). On the meanings of "nature". Paper presented at the Symposium on Children, Nature, and the Urban Environment - U.S. Department of Agriculture Northeastern Forest Experiment Station, Upper Darby, PA. 